\title{
СРАВНЕНИЕ УЧЕБНОЙ МАТРИЦЫ БАКАЛАВРИАТА ПО ХИМИИ В IFAP C СОДЕРЖАНИЕМ ENADE
}

\section{ОРИГИНАЛЬНАЯ СТАТЬЯ}

SANTOS, Lívia Maria Sousa dos ${ }^{1}$, TATY, Salvador Rodrigues², FERNANDES, Erlyson Farias $^{3}$, FECURY, Amanda Alves ${ }^{4}$, DENDASCK, Carla Viana ${ }^{5}$, OLIVEIRA, Euzébio $\mathrm{de}^{6}$, DIAS, Claudio Alberto Gellis de Mattos ${ }^{7}$

SANTOS, Lívia Maria Sousa dos. Et al. Сравнение учебной матрицы бакалавриата по химии в IFAP с содержанием ENADE. Revista Científica Multidisciplinar Núcleo do Conhecimento. Год 06, эд. 03, Vol. 14, стр. 29-40. Март 2021 года. ISSN: 2448-0959, Ссылка доступа: $\quad$ https://www.nucleodoconhecimento.com.br/образование-ru/матрицыбакалавриата , DOI: 10.32749/nucleodoconhecimento.com.br/ru/80986

\section{СВОДКА}

Учебная матрица представляет собой набор учебных компонентов (дисциплин), которые гарантируют содержание необходимого фрормирования студента в курсе

\footnotetext{
${ }^{1}$ Студент технического курса химии (вторая степень) Института базового, технического и технологического образования Amapá (IFAP).

${ }^{2}$ Химик, магистр химии (UFMA), профессор и исследователь курса химии Института базового, технического и технологического образования Amapá (IFAP), координатор технического курса по химии (IFAP).

${ }^{3}$ Химик, магистр химии (UFPA), профессор и исследователь курса химии Института базового, технического и технологического образования Amapá (IFAP).

${ }^{4}$ Биомедицин, доктор философии по тропическим болезням, профессор и исследователь курса медицины в Кампусе Макапа, Федеральный университет Amapá (UNIFAP).

${ }^{5}$ Богослов, кандидат клинических психоанализов. В течение 15 лет он работал с научной методологией (методом исследования) в научно-производственной ориентации магистрантов и докторантов.

Специалист в области маркетинговых исследований и медицинских исследований, докторант в области коммуникации и семиотики (PUC SP).

${ }^{6}$ Биолог, доктор тропических болезней, профессор и исследователь курса физического воспитания Федерального университета Pará (UFPA)

${ }^{7}$ Биолог, кандидат теоретических и летных исследований, профессор и исследователь курса химии Института базового, технического и технологического образования Атара́ (IFAP) и Высшей программы профессионального и технологического образования (PROFEPT IFAP).
}

RC: 80986

Ссылка доступа: https://www.nucleodoconhecimento.com.br/образование-ru/матрицы- 
и претерпевает постоянные изменения в связи со скоростью, с которой академически-технологические инновации представлены. Высший курс химии, предлагаемый Федеральным институтом Amapá, основан на его целях в условиях профессиональной подготовки студента в этом учебном заведении. Целью этой работы было сравнить содержание химии Национального экзамена по успеваемости студентов (ENADE) с учебной матрицей степени бакалавра химии Федерального института Amapá (IFAP) в 2011, 2014 и 2017 годах. Оценка ENADE для выпускников химии требует, чтобы обученный специалист знал конкретное содержание, как и ожидалось. Но она ищет в них знания, которые охватывают динамику класса. Исходя из этого, мы отмечаем пристрастие к определенным конкретным и неспецифическим предметам, ищущим информацию о практической подготовке студентов. Степень курса по химии в IFAP, как представляется, более чем достаточно рабочей нагрузки для студента, чтобы подготовиться и хорошо работать в ENADE.

Ключевые слова: Матрица учебной программы, ENADE, степень бакалавра, химия.

\section{ЗНАКОМСТВО}

Учебная матрица - это набор учебных компонентов (дисциплин), гарантируя содержание, необходимое для формирования студента на курсе. Эти компоненты будут охватывать обязательные и необязательные материалы. При поддержке PDI (План институционального развития) и PPC (Педагогический курс проекта) структурировать учебную программу на основе учебных и внеклассных стажировок, практических лабораторных классов (если таковые имеются), мониторинг, завершение курса работы, дополнительные мероприятия и желаемый профиль студента, который уже завершил курс и находится на рынке труда (egresso) (Carneiro et al., 2017).

Матрица учебной программы претерпевает постоянные изменения в связи со скоростью, с которой академические и технологические инновации $\mathrm{RC}: 80986$

Ссылка доступа: https://www.nucleodoconhecimento.com.br/образование-ru/матрицы- 
представлены, в результате чего необходимость изменений в учебной программе для обеспечения большего обучения в курсе, гарантируя, что студенты могут быть более квалифицированными и пригодными для рынка труда (Carneiro et al., 2017).

Высший курс химии, предлагаемый Федеральным институтом Amapá, основан на его целях в условиях профессиональной подготовки студента в этом учебном заведении. Технологические и научные знания будут предоставляться вместе с теоретическими и практическими основами во всех конкретных секторах химической области, способствуя подготовке квалифицированного специалиста, с тем самым выступать в качестве учителя химии в области базового образования в будущем, с большим акцентом на средней школе (Ifap, 2011).

Национальный экзамен по успеваемости студентов (ENADE) является экзаменом, применяемым к концу высшего образования для измерения знаний выпускников каждого курса. Это будет разделено на две части, общая, выполняемая всеми курсами данного года, измеряя когнитивные навыки, такие как интерпретация графиков, логические рассуждения и другие; и конкретная часть для каждого курса, измеряя конкретные знания. (Wainer e Melguizo, 2018). Экзамен проводится в цикле каждые три года и его применение является обязательным (Lima et al., 2019).

Он имеет право принять тест всех тех, кто представляет завершение семьдесят пять процентов или более минимальной рабочей нагрузки курса, в соответствии с тем, что предписано для выпускников высших учебных курсов технологии. Регистрация этого участника должна быть сделана Высшим учебным заведением (IES), в соответствии с No 6 ст. 5 Закона 10.861/2004 Зачисленный участник должен присутствовать в обязательном порядке по месту проведения теста, его отсутствие, без правдоподобного обоснования, принесет нарушения в историю школы, а также выдачу диплома о завершении курса (Enade, 2020).

RC: 80986

Ссылка доступа: https://www.nucleodoconhecimento.com.br/образование-ru/матрицы- 


\section{ЦЕЛЕЙ}

Сравните содержание химии Национального экзамена по успеваемости студентов (ENADE) с учебной матрицей курса высшего образования степени химии Федерального института Амапе (IFAP) в 2011, 2014 и 2017 годах.

\section{МАТЕРИАЛ И МЕТОДЫ}

Исследование проводилось с использованием вопросов Национального экзамена по успеваемости студентов (ENADE), взятых из всемирной компьютерной сети, с использованием инструмента поиска Google (http://inep.gov.br/educacao-superior/enade/provas-e-gabaritos) (Inep, 2020). Дисциплина химии степень была выбрана и лет 20112014 и 2017, используя поле (с годом) доступны на сайте. Впоследствии было сделано сравнение между этим и программным содержанием курса «Степень в химии» в Instituto Federal do Amapá, IFAP (https://www.ifap.edu.br/) (Ifap, 2011). Библиографические исследования проводились в научных статьях, в home office. Данные были собраны в приложение Excel, в состав набора Microsoft Corporation Office.

\section{РЕЗУЛЬТАТЫ}

Вопросы химии ENADE 2011, 2014 и 2017 по типу содержания каждого вопроса показаны на рисунке 1. Вопросы, содержащие только один тип контента (простое содержание), представляют собой 30 из 90 тестовых вопросов трех лет (33,33\%). Вопросы, которые имеют более одного содержания (перекрытия содержания) 60 из 90 вопросов $(66,67 \%)$.

RC: 80986

Ссылка доступа: https://www.nucleodoconhecimento.com.br/образование-ru/матрицы- 
На рисунке 1 - показан объем вопросов химии ENADE за 2011, 2014 и 2017 годы по типу содержания каждого вопроса.

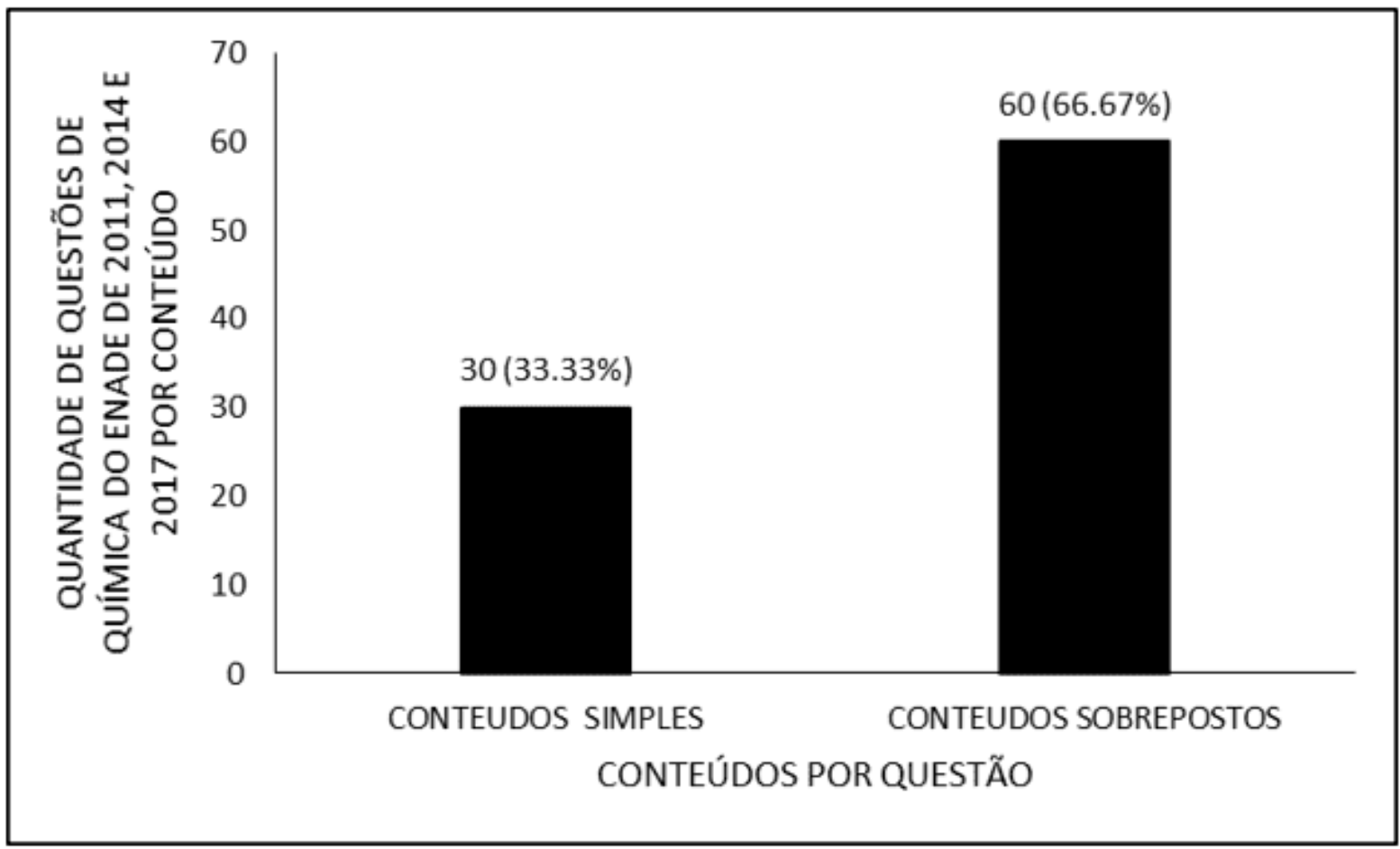

Таблица 1 показывает распределение (количество и процент) вопросов в содержании (простых и перекрывающихся), присутствующих в 2011, 2014 и 2017 ГОДАх ENADE, по вопросу. Среди вопросов с простым содержанием, 10 содержания не были предъявлены обвинения в оценках этих лет $(1,11 \%)$; пять содержание появилось один раз (2,22\%); содержание (органические соединения: реакции и механизмы; природные и синтетические макромолекулы) было предъявлено обвинение в трех вопросах (3,33\%); и еще один (государственная политика и их последствия для преподавания химии) было предъявлено обвинение семь раз (7,78\%). Среди наиболее присутствующих содержания, в трех вопросах (3,33\%), было "Учебные проекты и предложения в области преподавания химии и стратегии преподавания и оценки в области химии и их отношения с различными концепциями преподавания и обучения -

RC: 80986

Ссылка доступа: https://www.nucleodoconhecimento.com.br/образованиe-ru/матрицыбакалавриата 
дидактические ресурсы для преподавания химии". Другие комбинации узнают по одному в каждом вопросе.

Таблица 1 - показывает распределение (количество и процент) вопросов в содержании (простое и перекрываемое), присутствуют в ENADE 2011, 2014 и 2017 ,

\begin{tabular}{|c|c|c|}
\hline CONTEÚDOS SIMPLES & $\begin{array}{l}\text { Quantidade } \\
\text { de questôes }\end{array}$ & $\begin{array}{l}\text { Porcentagem } \\
\text { de questões }\end{array}$ \\
\hline Elementos químicos (química in orgânica) & 0 & $0.00 \%$ \\
\hline Estrutura molecular (química inorgânica) & 0 & $0.00 \%$ \\
\hline Estudo de substâncias e transformações químicas (físico-quimica) & 0 & $0.00 \%$ \\
\hline Métodos de análise em química: caracterização e quantificação & 0 & $0.00 \%$ \\
\hline Gases (química geral) & 0 & $0.00 \%$ \\
\hline Compostos inorgânicos de elementos representativos e de coordenação & 0 & $0.00 \%$ \\
\hline Bioquímica: estrutura de biomoléculas, biossíntese e metabolismo & 0 & $0.00 \%$ \\
\hline $\begin{array}{l}\text { Estratégias de ensino e de avaliação em Química e suas relações com as diferentes concepções de } \\
\text { ensino e aprendizagem }\end{array}$ & 0 & $0.00 \%$ \\
\hline Estrutura molecular e de sólidos iônicos e metálicos & 0 & $0.00 \%$ \\
\hline Compostos orgânicos + bioquímica & 0 & $0.00 \%$ \\
\hline Estrutura atômica (química geral) & 1 & $1.11 \%$ \\
\hline Química ambiental & 1 & $1.11 \%$ \\
\hline $\begin{array}{l}\text { A história da Química no contexto do desenvolvimento científico e tecnológico e a sua relação com o } \\
\text { ensino de Química }\end{array}$ & 1 & $1.11 \%$ \\
\hline Recursos didáticos para o ensino de Química & 1 & $1.11 \%$ \\
\hline Relações entre ciência, tecnologia, sociedade e ambiente no ensino de Química & 1 & $1.11 \%$ \\
\hline Estados dispersos: soluções e sistemas coloidais & 2 & $2.22 \%$ \\
\hline Termodinâmica (química geral) & 2 & $2.22 \%$ \\
\hline cinética química (química geral) & 2 & $2.22 \%$ \\
\hline $\begin{array}{c}\text { Normas de segurança e operações de laboratório utilizadas em síntese, purificação, caracterização e } \\
\text { quantificação de substâncias e em determinações físico-químicas }\end{array}$ & 2 & $2.22 \%$ \\
\hline Projetos e propostas curriculares no ensino de Química & 2 & $2.22 \%$ \\
\hline A experimentação no ensino de Química & 2 & $2.22 \%$ \\
\hline Eletroquímica (química geral) & 3 & $3.33 \%$ \\
\hline Compostos orgânicos: reações e mecanismos; macromoléculas naturais e sintéticas & 3 & $3.33 \%$ \\
\hline As políticas públicas e suas implicações para o ensino de Química & 7 & $7.78 \%$ \\
\hline TOTAL & 30 & $33.33 \%$ \\
\hline
\end{tabular}

RC: 80986

Ссылка доступа: https://www.nucleodoconhecimento.com.br/образование-ru/матрицы- 
CONTEÚDOS SOBREPOSTOS

Quantidade Porcentagem

\begin{tabular}{|c|c|c|}
\hline CONTEÚDOS SOBREPOSTOS & $\begin{array}{l}\text { Quantidade } \\
\text { de questōes }\end{array}$ & $\begin{array}{l}\text { Porcentagem } \\
\text { de questōes }\end{array}$ \\
\hline $\begin{array}{l}\text { Métodos de análise em química: caracterização e quantificação + Compostos orgânicos: reaçōes e } \\
\text { mecanismos; macromoléculas naturais e sintéticas + Bioquímica: estrutura de biomoléculas, } \\
\text { biossíntese e metabolismo + Química ambiental }\end{array}$ & 1 & $1.11 \%$ \\
\hline $\begin{array}{l}\text { Elementos químicos (química inorgânica) + Estrutura atômica (química geral) + Estrutura molecular } \\
\text { (química inongânica) + Compostos inorgânicos de elementos representativos e de coordenação + } \\
\text { Compostos orgânicos: reaçōes e mecanismos; macromoléculas naturais e sintéticas }\end{array}$ & 1 & $1.11 \%$ \\
\hline $\begin{array}{l}\text { Elementos químicos (química inorgânica) + Estudo de substâncias e transformaçōes químicas (físico- } \\
\text { química) + Gases (química geral) + Eletroquímica (química geral) }\end{array}$ & 1 & $1.11 \%$ \\
\hline $\begin{array}{l}\text { Estrutura atômica (química geral) + Estrutura molecular (química inorgânica) + Compostos inongânicos } \\
\text { de elementos representativos e de coordenação + Estrutura molecular e de sólidos iônicos e metálicos } \\
\text { + Elementos químicos (química inorgânica) }\end{array}$ & 1 & $1.11 \%$ \\
\hline $\begin{array}{c}\text { Elementos químicos (química inorgânica) + Estrutura atômica (química geral) + Eletroquímica (química } \\
\text { geral) + A história da Química no contexto do desenvolvimento científico e tecnológico e a sua relaçăo } \\
\text { como ensino de Química + Estrutura molecular e de sólidos iônicos e metálicos }\end{array}$ & 1 & $1.11 \%$ \\
\hline $\begin{array}{l}\text { Compostos orgânicos: reações e mecanismos; macromoléculas + Bioquímica: estrutura de } \\
\text { biomoléculas, biossíntese e metabolismo + Compostos orgânicos + bioquímica }\end{array}$ & 1 & $1.11 \%$ \\
\hline $\begin{array}{l}\text { Compostos ongânicos: reações e mecanismos; macromoléculas naturais e sintéticas + Bioquímica: } \\
\text { estrutura de biomoléculas, biossíntese e metabolismo + Compostos orgânicos + bioquímica }\end{array}$ & 1 & $1.11 \%$ \\
\hline $\begin{array}{l}\text { Elementos químicos (química inorgânica) +Estrutura molecular (química inorgânica) + Métodos de } \\
\text { análise em química: caracterização e quantificação + Compostos inorgânicos de elementos } \\
\text { representativos e de coordenaçăo + Estrutura molecular e de sólidos iônicos e metálicos }\end{array}$ & 1 & $1.11 \%$ \\
\hline $\begin{array}{l}\text { Métodos de análise em química: caracterização e quantificação + Química ambiental + Estudo de } \\
\text { substâncias e transformaçóes químicas (físico-química) }\end{array}$ & 1 & $1.11 \%$ \\
\hline $\begin{array}{c}\text { Estudo de substâncias e transformaçōes químicas (físico-química) + cinética química (química geral) + } \\
\text { Eletroquímica (química geral) + Compostos orgânicos: reaçōes e mecanismos; macromoléculas naturais } \\
\text { e sintéticas + Bioquímica: estrutura de biomoléculas, biossíntese e metabolismo + Compostos } \\
\text { orgânicos + bioquímica }\end{array}$ & 1 & $1.11 \%$ \\
\hline $\begin{array}{l}\text { Elementos químicos (química inorgânica) + Estudo de substâncias e transformações químicas (físico- } \\
\text { química) + Métodos de análise em química: caracterização e quantificação + Química ambiental + A } \\
\text { experimentação no ensino de Química }\end{array}$ & 1 & $1.11 \%$ \\
\hline $\begin{array}{c}\text { Projetos e propostas curriculares no ensino de Química + As políticas públicas e suas implicações para o } \\
\text { ensino de Química }\end{array}$ & 1 & $1.11 \%$ \\
\hline $\begin{array}{c}\text { Projetos e propostas curriculares no ensino de Química + Estratégias de ensino e de avaliaçāo em } \\
\text { Química e suas relaçōes com as diferentes concepçōes de ensino e aprendizagem + Recursos didáticos } \\
\text { para o ensino de Química }\end{array}$ & 1 & $1.11 \%$ \\
\hline $\begin{array}{l}\text { Projetos e propostas curriculares no ensino de Química + Recursos didáticos para o ensino de Química + } \\
\text { As políticas públicas e suas implicações para o ensino de Química }\end{array}$ & 1 & $1.11 \%$ \\
\hline $\begin{array}{l}\text { Projetos e propostas curriculares no ensino de Química + Relaçōes entre ciência, tecnologia, sociedade } \\
\text { e ambiente no ensino de Química + A experimentação no ensino de Química + As políticas públicas e } \\
\text { suas implicaçōes para o ensino de Química }\end{array}$ & 1 & $1.11 \%$ \\
\hline $\begin{array}{c}\text { Projetos e propostas curriculares no ensino de Química + As políticas públicas e suas implicações para o } \\
\text { ensino de Química }\end{array}$ & 1 & $1.11 \%$ \\
\hline
\end{tabular}

RC: 80986

Ссылка доступа: https://www.nucleodoconhecimento.com.br/образование-ru/матрицы- 


\begin{tabular}{|c|c|c|}
\hline CONTEÚDOS SOBREPOSTOS & $\begin{array}{l}\text { Quantidade } \\
\text { de questŏes }\end{array}$ & $\begin{array}{l}\text { Porcentagem } \\
\text { de questões }\end{array}$ \\
\hline $\begin{array}{l}\text { Estrutura atômica (química ge ral) + Eletroquímica (química geral) + A história da Química no contexto do } \\
\text { desenvolvimento científico e tecnológico e a sua relação com o ensino de Química + Relações entre } \\
\text { ciência, tecnologia, sociedade e ambiente no ensino de Química }\end{array}$ & 1 & $1.11 \%$ \\
\hline $\begin{array}{l}\text { Métodos de análise em química: caracterização e quantificação + Química ambiental + Relações entre } \\
\text { ciência, tecnologia, sociedade e ambiente no ensino de Química + As políticas públicas e suas } \\
\text { implicações para o ensino de Química }\end{array}$ & 1 & $1.11 \%$ \\
\hline $\begin{array}{l}\text { Elementos químicos (química inorgânica) + Estrutura atômica (química geral) + Estrutura molecular } \\
\text { (química inorgânica) + Métodos de análise em química: caracterização e quantificação + Compostos } \\
\text { orgânicos: reações e mecanismos; macromoléculas naturais e sintéticas + Bioquímica: estrutura de } \\
\text { biomoléculas, biossíntese e metabolismo + Compostos orgânicos + bioquímica }\end{array}$ & 1 & $1.11 \%$ \\
\hline $\begin{array}{l}\text { Elementos químicos (química inorgânica) + Estrutura atômica (química geral) + Estrutura molecular } \\
\text { (química inorgânica) + Métodos de análise em química: caracterização e quantificação + Compostos } \\
\text { inorgânicos de elementos representativos e de coordenação + Estratégias de ensino e de avaliação em } \\
\text { Química e suas relações com as dife rentes concepções de ensino e aprendizagem + Recursos didáticos } \\
\text { para o ensino de Química + A experimentação no ensino de Química }\end{array}$ & 1 & $1.11 \%$ \\
\hline $\begin{array}{c}\text { Estudo de substâncias e transformações químicas (físico-química) + Termodinâmica (química geral) + } \\
\text { Eletroquímica (química geral) }\end{array}$ & 1 & $1.11 \%$ \\
\hline $\begin{array}{l}\text { Métodos de análise em química: caracterização e quantificação + Estados dispersos: soluções e } \\
\qquad \text { sistemas coloidais + Química ambiental }\end{array}$ & 1 & $1.11 \%$ \\
\hline Estudo de substâncias e transformações químicas (físico-química) + Gases (química geral) & 1 & $1.11 \%$ \\
\hline $\begin{array}{c}\text { Elementos químicos (química inorgânica) + Estrutura molecular (química inorgânica) + Compostos } \\
\text { inorgânicos de elementos representativos e de coordenação + Estrutura molecular e de sólidos iônicos } \\
\text { e metálicos }\end{array}$ & 1 & $1.11 \%$ \\
\hline Estudo de substâncias e transformações químicas (físico-química) + Termodinâmica (química geral) & 1 & $1.11 \%$ \\
\hline $\begin{array}{l}\text { Estados dispersos: soluções e sistemas coloidais + Estratégias de ensino e de avaliação em Química e } \\
\text { suas relações com as diferentes concepções de ensino e aprendizagem + Recursos didáticos para o } \\
\text { ensino de Química + A experimentação no ensino de Química }\end{array}$ & 1 & $1.11 \%$ \\
\hline Métodos de análise em química: caracterização e quantificação + Química ambiental & 1 & $1.11 \%$ \\
\hline $\begin{array}{l}\text { Estrutura molecular (química inorgânica) + Métodos de análise em química: caracterização e } \\
\text { quantificação + Compostos orgânicos: reações e mecanismos; macromoléculas naturais e sintéticas }\end{array}$ & 1 & $1.11 \%$ \\
\hline $\begin{array}{l}\text { Estudo de substâncias e transformações químicas (físico-química) + Métodos de análise em química: } \\
\text { caracterização e quantificação + Química ambiental }\end{array}$ & 1 & $1.11 \%$ \\
\hline
\end{tabular}

RC: 80986

Ссылка доступа: https://www.nucleodoconhecimento.com.br/образование-ru/матрицы- 


\begin{tabular}{|c|c|c|}
\hline $\begin{array}{l}\text { Compostos orgânicos: reações e mecanismos; macromoléculas naturais e sintéticas + Bioquímica: } \\
\text { estrutura de biomoléculas, biossíntese e metabolismo + Compostos orgânicos + bioquímica }\end{array}$ & 1 & $1.11 \%$ \\
\hline $\begin{array}{l}\text { Estrutura molecular (química inorgânica) + Métodos de análise em química: caracterização e } \\
\text { quantificação + Compostos orgânicos: reações e mecanismos; macromoléculas naturais e sintéticas + } \\
\text { Bioquímica: estrutura de biomoléculas, biossíntese e metabolismo + Compostos orgânicos + bioquímica }\end{array}$ & 1 & $1.11 \%$ \\
\hline $\begin{array}{l}\text { Elementos químicos (química inorgânica) + estrutura atômica (química ge ral) + Estrutura molecular } \\
\text { (química inorgânica) + Termodinâmica (química geral) + Compostos inorgânicos de elementos } \\
\text { representativos e de coordenação + Compostos orgânicos: reações e mecanismos; macromoléculas } \\
\text { naturais e sintéticas + Bioquímica: estrutura de biomoléculas, biossíntese e metabolismo + Estrutura } \\
\text { molecular e de sólidos iônicos e metálicos + Compostos orgânicos + bioquímica }\end{array}$ & 1 & $1.11 \%$ \\
\hline $\begin{array}{c}\text { Termodinâmica (química geral) + Compostos orgânicos: reações e mecanismos; macromoléculas } \\
\text { naturais e sintéticas }\end{array}$ & 1 & $1.11 \%$ \\
\hline $\begin{array}{l}\text { Projetos e propostas curriculares no ensino de Química + as políticas públicas e suas implicações para o } \\
\text { ensino de Química }\end{array}$ & 1 & $1.11 \%$ \\
\hline $\begin{array}{l}\text { Estratégias de ensino e de avaliação em Química e suas relações com as dife rentes concepções de } \\
\text { ensino e aprendizagem + as políticas públicas e suas implicações para o ensino de Química }\end{array}$ & 1 & $1.11 \%$ \\
\hline $\begin{array}{l}\text { Projetos e propostas curriculares no ensino de Química + Estratégias de ensino e de avaliação em } \\
\text { Química e suas relações com as diferentes concepções de ensino e aprendizagem }\end{array}$ & 1 & $1.11 \%$ \\
\hline $\begin{array}{l}\text { Projetos e propostas curriculares no ensino de Química + Estratégias de ensino e de avaliação em } \\
\text { Química e suas relações com as diferentes concepções de ensino e aprendizagem + as políticas públicas } \\
\text { e suas implicações para o ensino de Química }\end{array}$ & 1 & $1.11 \%$ \\
\hline $\begin{array}{l}\text { Estudo de substâncias e transformações químicas (físico-química) + Métodos de análise em química: } \\
\text { caracte rização e quantificação + Eletroquímica (química geral) }\end{array}$ & 1 & $1.11 \%$ \\
\hline
\end{tabular}

RC: 80986

Ссылка доступа: https://www.nucleodoconhecimento.com.br/образование-ru/матрицы- 
Cinética química (química geral) + Bioquímica: estrutura de biomoléculas, biossíntese e metabolismo

Elementos químicos (química inorgânica) + Estrutura molecular (química inorgânica) + Gases (química geral) + Compostos inorgânicos de elementos representativos e de coordenação + Estrutura molecular e de sólidos iônicos e metálicos

\begin{tabular}{|c|c|c|}
\hline e de sólidos iônicos e metálicos & & \\
\hline $\begin{array}{l}\text { Estrutura molecular (química inorgânica) + Compostos orgâni cos: reações e mecanismos; } \\
\text { macromoléculas naturais e sintéticas + Compostos orgânicos + bioquímica }\end{array}$ & 1 & $1.11 \%$ \\
\hline $\begin{array}{c}\text { Elementos químicos (química inorgânica) + Estrutura atômica (química geral) + Estrutura mol ecular } \\
\text { (química inorgânica) + Eletroquímica (química geral) }\end{array}$ & 1 & $1.11 \%$ \\
\hline $\begin{array}{c}\text { Estrutura atômica (química geral) + Métodos de análise em química: caracterização e quantificação + } \\
\text { Compostos inorgâni cos de elementos representativos e de coordenaç̧ão + A experimentação no ensino } \\
\text { de Química }\end{array}$ & 1 & $1.11 \%$ \\
\hline $\begin{array}{c}\text { Métodos de análise em química: caracte rização e quantificação + A experimentação no ensino de } \\
\text { Química }\end{array}$ & 1 & $1.11 \%$ \\
\hline Termodinâmica (química geral) + Eletroquímica (química geral) & 1 & $1.11 \%$ \\
\hline $\begin{array}{l}\text { Estudo de substâncias e transformações químicas (físico-química) + Termodinâmica (química geral) + } \\
\text { cinética química (química geral) }\end{array}$ & 1 & $1.11 \%$ \\
\hline Cinética química (química geral) + Bioquímica: estrutura de biomoléculas, biossíntese e metabolismo & 1 & $1.11 \%$ \\
\hline Termodinâmica (química geral) + Gases (química geral) & 1 & $1.11 \%$ \\
\hline $\begin{array}{l}\text { Métodos de análise em química: caracterização e quantificação + Compostos orgânicos: reações e } \\
\text { mecanismos; macromoléculas naturais e sintéticas + Bioquímica: estrutura de biomoléculas, } \\
\text { biossíntese e metabolismo + Compostos orgânicos + bioquímica }\end{array}$ & 1 & $1.11 \%$ \\
\hline $\begin{array}{c}\text { Métodos de análise em química: caracterização e quantificação + cinética química (química geral) + } \\
\text { Compostos orgânicos: reações e mecanismos; macromoléculas naturais e sintéticas + A } \\
\text { experimentação no ensino de Química }\end{array}$ & 1 & $1.11 \%$ \\
\hline $\begin{array}{l}\text { Compostos orgânicos: reações e mecanismos; macromoléculas naturais e sintéticas + Bioquímica: } \\
\text { estrutura de biomoléculas, biossíntese e metabolismo + A experimentação no ensino de Química + } \\
\text { Compostos orgânicos + bioquímica }\end{array}$ & 1 & $1.11 \%$ \\
\hline $\begin{array}{l}\text { Estratégias de ensino e de avaliação em Química e suas relações com as diferentes concepções de } \\
\text { ensino e aprendizagem + Recursos didáticos para o ensino de Química }\end{array}$ & 1 & $1.11 \%$ \\
\hline $\begin{array}{l}\text { Projetos e propostas curriculares no ensino de Química + Relações entre ciência, tecnologia, sociedade } \\
\qquad \text { e ambiente no ensino de Química }\end{array}$ & 1 & $1.11 \%$ \\
\hline Projetos e propostas curriculares no ensino de Química + Recursos didáticos para o ensino de Química & 1 & $1.11 \%$ \\
\hline $\begin{array}{l}\text { Estudo de substâncias e transformações químicas (físico-química) + Métodos de análise em química: } \\
\text { caracterização e quantificação + Termodi nâmica (química geral) }\end{array}$ & 1 & $1.11 \%$ \\
\hline
\end{tabular}

RC: 80986

Ссылка доступа: https://www.nucleodoconhecimento.com.br/образованиe-ru/матрицы- 


\begin{tabular}{|c|c|c|}
\hline $\begin{array}{c}\text { A experimentação no ensino de Química + termodinâmica (química geral) + Métodos de análise em } \\
\text { quími ca: caracterização e quantificação + Estudo de substâncias e transformações químicas (físico- } \\
\text { química) }\end{array}$ & 1 & $1.11 \%$ \\
\hline $\begin{array}{l}\text { Elementos químicos (química inorgânica) + Estrutura atômica (química geral) + Estrutura molecular } \\
\text { (química inorgânica) + Estudo de substâncias e transformações químicas (físico-química) + Métodos de } \\
\text { análise em química: caracterização e quantificação + El etroquímica (química geral) + Estratégias de } \\
\text { ensino e de avaliação em Química e suas relações com as diferentes concepçães de ensinoe } \\
\text { aprendizagem + Estrutura molecular e de sólidos iônicos e metálicos }\end{array}$ & 1 & $1.11 \%$ \\
\hline $\begin{array}{l}\text { Projetos e propostas curriculares no ensino de Química + Estratégias de ensino e de avaliação em } \\
\text { Química e suas relaçães com as diferentes concepções de ensino e aprendizagem + Recursos didáticos } \\
\text { para o ensino de Química }\end{array}$ & 3 & $3.33 \%$ \\
\hline TOTAL & 60 & $66.67 \%$ \\
\hline
\end{tabular}

Содержимое, которое имеет самое длительное время в матрице бакалавриата курса по химии Федерального института образования, науки и техники Amapá (IFAP), Масара́ кампуса, с учетом 400 часов в комнате каждого периода, является контролируемым стажировки в преподавании химии І. Этот курс имеет 160 часов и составляет $40 \%$ от общего числа часов 6 -го периода и $6,67 \%$ от общего количества часов курса.

Далее далее будут далее далее далее далее далее будут казаться Основы химии и социально-исторические основы образования (1-й период); Философия образования и профессиональной этики (2-й период); Психология образования (3-й период); Генерал Дидактика (4-й период); Количественная аналитическая химия и законодательство и государственная политика (5-й период). Каждый из них составляет 80 часов часов, $20 \%$ от общего количества часов их соответствующих периодов и $3,33 \%$ от общего количества часов курса.

Такие материалы, как методология научной работы и коммуникации и языка (1-й период); Общая химия I, фризика I, диффреренциальный и интегральный исчисление I и линейная алгебра и аналитическая геометрия (2-й период); Общая химия II, физико-химия I, фризика II и диффреренциальный и интегральный исчисление II (3-й период); Физико-химическая химия II, неорганическая химия I; Органическая химия I; и качественная аналитическая химия (4-й период); Неорганическая химия II и органическая химия II (5-й период) составляют 60

RC: 80986

Ссылка доступа: https://www.nucleodoconhecimento.com.br/образование-ru/матрицы- 
часов рабочей нагрузки, $15 \%$ от общего количества часов их соответствующих периодов и $2,50 \%$ от общего количества часов курса.

Другие дисциплины (содержание) составляют 40 часов рабочей нагрузки, $10 \%$ от общего количества часов их соответствующих периодов и 1,67\% от общего количества часов курса (таблица 2).

В таблице 2 показано распределение дисциплин (содержимого) курса бакалавриата по химии Федерального института образования, науки и техники Амапе (IFAP), кампуса Масара́. Каждый контент показывает свою рабочую нагрузку, процент в течение периода и его процент, относящийся к всему курсу.

\begin{tabular}{|c|c|c|c|c|c|c|c|c|c|}
\hline \multicolumn{10}{|c|}{ MATRIZ CURRICULAR DO CURSO DE GRADUAÇÃo - LICENCIATURA EM QUÍMICA Instituto Fe deral de Educação, Ciência e Tecnologia do Amapá (IFAP) - Campus Macapá } \\
\hline \multirow{8}{*}{$\begin{array}{l}\text { 을 } \\
\text { 음 } \\
\text { 뜸 } \\
\text { 익 }\end{array}$} & Componente Curricular & Carga Horária & $\begin{array}{c}\text { \% disciplina } \\
\text { no período }\end{array}$ & \begin{tabular}{|c|}
$\begin{array}{c}\% \text { disciplina } \\
\text { no curso }\end{array}$ \\
\end{tabular} & \multirow{8}{*}{ 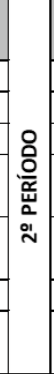 } & Componente Curricular & Carga Horária & $\begin{array}{c}\text { \% disciplina } \\
\text { no período }\end{array}$ & $\begin{array}{c}\% \text { disciplina } \\
\text { no curso }\end{array}$ \\
\hline & Fundamentos da Química & 80 & $20 \%$ & $3.33 \%$ & & Química Geral I & 60 & $15 \%$ & $2.50 \%$ \\
\hline & Fundamentos da Física & 40 & $10 \%$ & $1.67 \%$ & & Oficina Pedagógica de Química & 40 & $10 \%$ & $1.67 \%$ \\
\hline & Fundamentos da Matemática & 40 & $10 \%$ & $1.67 \%$ & & Físical & 60 & $15 \%$ & $2.50 \%$ \\
\hline & $\begin{array}{l}\text { Fundamentos Sócio-Históricos } \\
\text { da Educação }\end{array}$ & 80 & $20 \%$ & $3.33 \%$ & & Cáculo Diferencial e integral I & 60 & $15 \%$ & $2.50 \%$ \\
\hline & $\begin{array}{c}\text { Metodologia do Trabal ho } \\
\text { Cientifico }\end{array}$ & 60 & $15 \%$ & $2.50 \%$ & & $\begin{array}{c}\text { Álgebra Linear e Geometria } \\
\text { Analítica }\end{array}$ & 60 & $15 \%$ & $2.50 \%$ \\
\hline & Comunicação e Linguagem & 60 & $15 \%$ & $2.50 \%$ & & Informática Básica & 40 & $10 \%$ & $1.67 \%$ \\
\hline & Inglês Instrumental & 40 & $10 \%$ & $1.67 \%$ & & $\begin{array}{c}\text { Filosofia da Educação e Ética } \\
\text { Profissional }\end{array}$ & 80 & $20 \%$ & $3.33 \%$ \\
\hline \multirow{8}{*}{ 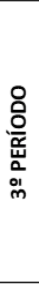 } & Componente Curricular & Carga Horária & $\begin{array}{c}\text { \% disciplina } \\
\text { no período }\end{array}$ & $\begin{array}{l}\text { \% disciplina } \\
\text { no curso }\end{array}$ & \multirow{8}{*}{ 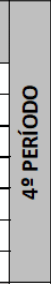 } & Componente Curricular & Carga Horária & $\begin{array}{c}\text { \% disciplina } \\
\text { no período }\end{array}$ & $\begin{array}{l}\text { \% disciplina } \\
\text { no curso }\end{array}$ \\
\hline & Química Geral II & 60 & $15 \%$ & $2.50 \%$ & & Físico-Química II & 60 & $15 \%$ & $2.50 \%$ \\
\hline & Química Geral Experimental & 40 & $10 \%$ & $1.67 \%$ & & Físico-Química Experimental & 40 & $10 \%$ & $1.67 \%$ \\
\hline & Físico-Química I & 60 & $15 \%$ & $2.50 \%$ & & Química Inorgânica I & 60 & $15 \%$ & $2.50 \%$ \\
\hline & Física II & 60 & $15 \%$ & $2.50 \%$ & & Química Orgânica I & 60 & $15 \%$ & $2.50 \%$ \\
\hline & Cálculo Diferencial e Integral II & 60 & $15 \%$ & $2.50 \%$ & & Química Analítica Quantitativa & 60 & $15 \%$ & $2.50 \%$ \\
\hline & Probabilidade e Estatísitica & 40 & $10 \%$ & $1.67 \%$ & & Física Experimental & 40 & $10 \%$ & $1.67 \%$ \\
\hline & Piscologia da Educação & 80 & $20 \%$ & $3.33 \%$ & & Didática Geral & 80 & $20 \%$ & $3.33 \%$ \\
\hline \multirow{8}{*}{$\begin{array}{l}\text { 음 } \\
\text { 음 } \\
\text { 뗨 } \\
\text { in }\end{array}$} & Componente Curricular & Carga Horária & $\begin{array}{c}\text { \% disciplina } \\
\text { no período }\end{array}$ & $\begin{array}{l}\text { \% disciplina } \\
\text { no curso }\end{array}$ & \multirow{8}{*}{$\begin{array}{l}\text { 음 } \\
\text { 음 } \\
\text { 뗨 } \\
\text { 잉 }\end{array}$} & Componente Curricular & Carga Horária & $\begin{array}{l}\text { \% disciplina } \\
\text { no período }\end{array}$ & $\begin{array}{l}\text { \% disciplina } \\
\text { no curso }\end{array}$ \\
\hline & Química Inorgânica II & 60 & $15 \%$ & $2.50 \%$ & & Bioquímica I & 40 & $10 \%$ & $1.67 \%$ \\
\hline & Química Orgânica II & 60 & $15 \%$ & $2.50 \%$ & & Química Orgânica Experimental & 40 & $10 \%$ & $1.67 \%$ \\
\hline & $\begin{array}{c}\text { Química Analítica Quantitativa } \\
\text { Experimental }\end{array}$ & 40 & $10 \%$ & $1.67 \%$ & & Química Inorgânica Experimental & 40 & $10 \%$ & $1.67 \%$ \\
\hline & Química Analítica Quantitativa & 80 & $20 \%$ & $3.33 \%$ & & $\begin{array}{l}\text { Química Analítica Quantitativa } \\
\text { Experimental }\end{array}$ & 40 & $10 \%$ & $1.67 \%$ \\
\hline & Oficina Pedagógica de Química II & 40 & $10 \%$ & $1.67 \%$ & & $\begin{array}{c}\text { Estágio Supervisonado em } \\
\text { Ensino em Química I }\end{array}$ & 160 & $40 \%$ & $6.67 \%$ \\
\hline & Legislação e Políticas Públicas & 80 & $20 \%$ & $3.33 \%$ & & Didática A plicada à Química & 40 & $10 \%$ & $1.67 \%$ \\
\hline & $\begin{array}{c}\text { Tecnologias da Informação e } \\
\text { Comunicação Aplicadas à } \\
\text { Química }\end{array}$ & 40 & $10 \%$ & $1.67 \%$ & & $\begin{array}{l}\text { Currículo e Avaliação da } \\
\text { Aprendizagem }\end{array}$ & 40 & $10 \%$ & $1.67 \%$ \\
\hline
\end{tabular}

\section{ОБСУЖДЕНИЯ}

RC: 80986

Ссылка доступа: https://www.nucleodoconhecimento.com.br/образование-ru/матрицы- 
В данных, представленных на рисунке 1, можно отметить большее предпочтение предметам, требующим междисциплинарности, поскольку эти вопросы требуют знаний, которые интегрируют различное содержание для решения. Это становится важным, потому что способность соединять различные предметы, как представляется, обеспечить более прочное обучение, и в то же время помогает строить научные знания человека. Экзамен взимает академических присоединиться к индивидуальным знаниям каждого предмета и одновременно согласовать с другими дисциплинами (SOUSA et al , 2017). Недисциплинированность вопросов гарантирует, что академик интерпретирует проблемы, связывающие их с повседневной жизнью, позволяя взаимосвязанность знаний в различных областях (Coelho e Scremin, 2019; Carmo et al., 2021; Gortz et al., 2021).

ENADE обеспокоен тем, что студент окончил высший курс по химии понимает законы, которые регулируют преподавание этой дисциплины, и как эти нормы влияют на это учение (таблица 1). Подготовка профессионального критического и знаюго норм и образовательной реальности, в которой он работает, может привести к тому, что этот учитель внесет значительный вклад в значительное улучшение методов преподавания химии, в результате чего скорость знаний возрастет вместе с улучшением жизни студентов (Pontes et al., 2008).

Другая проблема, присутствуют в анализируемых испытаний с органическим составом живых существ (таблица 1). Химические реакции заставляют клетки работать, поэтому, если учитель химии знает клеточное функционирование, он может более близко объяснить функцию органических молекул повседневной жизни студентов (Leite и Velani, 2019). Размещение содержимого в перспективе изо дня в день студентов помогает понять эти молекулы и их процессы (Hipólito e Silveira, 2011; Silveira et al., 2014).

Кроме того, в таблице 1, 3,33\% перекрывающихся вопросов связаны со знанием дизайна проекта, стратегии преподавания и оценки в области химии. Профессиональная подготовка в высших учебных заведениях в бакалавриате, RC: 80986

Ссылка доступа: https://www.nucleodoconhecimento.com.br/образование-ru/матрицы- 
как правило, интегрирует академические знания с другими более конкретными по содержанию химии. Участие преподавателей в профессиональной подготовке, по-прежнему во время высшего образования, в контролируемых стажировках и в программах научного посвящения, продвигаемых федерацией, как представляется, вносит значительный вклад в их критический и академический содержание. Это позволило бы улучшить характеристики, заряженные в этих вопросах (Rosa et al., 2018).

Данные свидетельствуют о том, что основным содержанием, собранным в ENDADE в этот период, были государственная политика, органический состав живых существ, проектирование проектов, стратегии преподавания и оценка химии (таблица 1). Учебная матрица курса по химии в IFAP, как представляется, поддерживает эти знания (таблица 2). Контролируемая стажировка, общая дидактика и законодательство и государственная политика соответствуют 13\% (400 часов) от общего количества часов курса. Органическая химия I и II имеют 160 часов вместе и 5\% от общего количества часов курса. Таким образом, План педагогического курса (PРC), как считало коллегиальное учреждение, в котором он находится, соответствует изменениям в федеральном законодательстве, регулирующего подготовку преподавателей на курсах бакалавриата. Курс проанализировал уважает регионы, и это отражается в типе подготовки своих студентов (Santos et al., 2020).

\section{ЗАКЛЮЧЕНИЕ}

Оценка ENADE для выпускников химии требует, чтобы обученный специалист, как и ожидалось, знал о конкретном содержании (например, органической химии). Тем не менее, он ищет в них знания, которые охватывают динамику класса (что касается типа класса, оценки, как думать о учебной матрицы, как внести свой вклад в изменения для улучшения преподавания, как оценить содержание). Исходя из этого, существует пристрастие к определенным конкретным и неспецифическим предметам, ищущим информацию о практической подготовке студентов RC: 80986

Ссылка доступа: https://www.nucleodoconhecimento.com.br/образование-ru/матрицы- 
Степень курса по химии Instituto Federal do Amapá, IFAP, кажется, более чем достаточно рабочей нагрузки, так что студент может подготовиться и хорошо работать в ENADE, потому что следует, с улучшениями, что регулирует федеральный стандарт для этого типа курса.

\section{ссылки}

CARMO, D. R. D. et al. A física no enem e no curso técnico de química do instituto federal do amapá (IFAP): Uma comparação curricular. Revista Científica Multidisciplinar Núcleo do Conhecimento, v. 3, p. 80-88, 2021. Disponível em: < https://www.nucleodoconhecimento.com.br/educacao/fisica-no-enem >.

CARNEIRO, J. D. et al. Matriz Curricular para Cursos de Ciências Contábeis. Brasilia DF: Fundação Brasileira de Contabilidade, 2017. 208p.

COELHO, F. B. O.; SCREMIN, G. A Interdisciplinaridade nas Licenciaturas em Ciências da Natureza: Análise de Projetos Pedagógicos de Cursos. XII Encontro Nacional de Pesquisa em Educação em Ciências - XII ENPEC Natal, RN: Universidade Federal do Rio Grande do Norte 2019.

ENADE. Antes da Prova, 2020. Brasilia DF, 2020. Disponível em: < https://www.gov.br/inep/pt-br/acesso-a-informacao/perguntas-frequentes/examenacional-de-desempenho-dos-estudantes-enade >. Acesso em: 02 fev 2021.

GORTZ, J. S. et al. Química do ensino médio técnico e enem: Uma comparação curricular. Revista Científica Multidisciplinar Núcleo do Conhecimento, v. 3, p. 8999, 2021.

Disponível em:

https://www.nucleodoconhecimento.com.br/educacao/comparacao-curricular >.

HIPÓLITO, A. F.; SILVEIRA, H. E. D. As questões de Química do Exame Nacional do Ensino Médio (ENEM) em um enfoque transversal e interdisciplinar. 2011. Disponível em: < http://abrapecnet.org.br/atas_enpec/viiienpec/resumos/R0237-1.pdf >. Acesso em: 11 fev 2021.

RC: 80986

Ссылка доступа: https://www.nucleodoconhecimento.com.br/образование-ru/матрицыбакалавриата 
IFAP. PPC Licenciatura em Química. Macapá AP, 2011. Disponível em: < https://macapa.ifap.edu.br/index.php/mais-noticias/395-licenciatura-em-quimica >. Acesso em: 02 fev 2021.

INEP. Provas e Gabaritos ENADE, 2020. Brasilia DF, 2020. Disponível em: < http://inep.gov.br/educacao-superior/enade/provas-e-gabaritos >. Acesso em: 14 jul 2020.

LEITE, K. D. C.; VELANI, V. Divertindo-se com a química: o ensino e a aprendizagem por meio do lúdico. Braz. J. of Develop., v. 5, n. 11, p. 25115-25133, 2019.

LIMA, P. D. S. N. et al. Análise de dados do Enade e Enem: uma revisão sistemática da literatura. Avaliação (Campinas), v. 24, n. 1, p. 89-107, 2019.

PONTES, A. N. et al. O Ensino de Química no Nível Médio: Um Olhar a Respeito da Motivação. XIV Encontro Nacional de Ensino de Química (XIV ENEQ) Curitiba PR: Universidade Federal do Paraná 2008.

ROSA, D. L.; MENDES, A. N. F.; LOCATELLI, A. B. A formação da identidade docente na licenciatura em química e suas relações com a aprendizagem significativa a partir da análise do Modelo de Ensino de Gowin. Revista Práxis, v. 10, n. 20, dez., 2018, v. $10, \quad$ n. 20, p. 1-14, 2018. Disponível em: < http://revistas.unifoa.edu.br/index.php/praxis/article/view/830/2237 >.

SANTOS, D. R. C. M. D.; LIMA, L. P.; JUNIOR, G. G. A formação de professores de química, mudanças na regulamentação e os impactos na estrutura em cursos de licenciatura em química. Quim. Nova, v. 43, n. 7, p. 977-986, 2020. Disponível em: < https://www.scielo.br/pdf/qn/v43n7/0100-4042-qn-43-07-0977.pdf >.

SILVEIRA, F. L.; STILCK, J.; BARBOSA, M. Comunicações: Manifesto sobre a qualidade das questões de Física na Prova de Ciências da natureza no Exame Nacional de Ensino Médio. Caderno Brasileiro de Ensino de Física, v. 31, n. 2, p. 473-479, 2014.

RC: 80986

Ссылка доступа: https://www.nucleodoconhecimento.com.br/oбразование-ru/матрицы- 
WAINER, J.; MELGUIZO, T. Políticas de inclusão no ensino superior: avaliação do desempenho dos alunos baseado no Enade de 2012 a 2014. Educ. Pesqui., v. 44, p. e162807, 2018.

Представлено: Март, 2021.

Утверждено: Март, 2021.

RC: 80986

Ссылка доступа: https://www.nucleodoconhecimento.com.br/образование-ru/матрицыбакалавриата 